九州大学学術情報リポジトリ

Kyushu University Institutional Repository

\title{
Several Characteristics of Hydraulic Jump Controlled by the Subdam
}

Kato, Osamu

Laboratory of Land-Drainage and Reclamation, Faculty of Agriculture, Kyushu University

Tanaka, Kohe i

Laboratory of Land-Drainage and Reclamation, Faculty of Agriculture, Kyushu University

Tohara, Yoshio

Laboratory of Land-Drainage and Reclamation, Faculty of Agriculture, Kyushu University

Hasegawa, Koichi

Laboratory of Land-Drainage and Reclamation, Faculty of Agriculture, Kyushu University

他

https://doi.org/10.5109/23494

出版情報：九州大学大学院農学研究院紀要. 21 (2/3)，pp.141-152，1977-03. Kyushu University バージョン：

権利関係 : 


\title{
Several Characteristics of Hydraulic Jump Controlled by the Subdam
}

\author{
Osamu Kato*, Kohei Tanaka, Yoshio Tohara*, \\ Kōichi Hasegawa and Itaru Uesato
}

\author{
Laboratory of Land-Drainage and Reclamation, Faculty \\ of Agriculture, Kyushu University 46-05, Fukuoka 812
}

(Received December 15, 1976)

\begin{abstract}
Water stored in a dam has far larger potential energy than the flow-water in river before banking. So, it is important to dissipate energy in water flowing over dam, chute and other hydraulic structures and thus prevent scouring downstream from structures. From a practical viewpoint, hydraulic jump is a useful means of dissipating the energy. The hydraulic jump used for energy dissipation is usually confined to the stilling basin. Furthermore, in order to control the jump, the accessories are usually installed in the basin to shorten the range in which the jump will take place. In this investigation, subdam was used as accessory to control the jump. The objective of this study was to investigate the methods for determining the height of subdam, its setting place, and its downstream depth.
\end{abstract}

\section{THEORETICAL ANALYSIS}

\section{Methods for determining the height of subdam}

According to Iwasaki (1961), the height of subdam is theoretically represented in the following equation:

$$
{ }_{h_{1}}^{d}-\frac{\left(1+2 F^{2}\right) \sqrt{1+8 F^{2}}-1-5 F^{2}}{1+4 F^{2}-\sqrt{1+8 F^{2}}}-\frac{3}{2} F^{2}
$$

where $h_{1}$ is the depth at the beginning point of a jump, $d$ is the height of subdam and $F\left(=v_{1} / \sqrt{g h}\right)$ is the Froude number using the mean velocity $\left(v_{1}\right)$ at the beginning point of a jump (the toe of the roller).

This equation is derived from the following assumptions:

(i) the momentum is conserved between sections I and II in Fig. 1,

(ii) energy losses are negligible between sections II and III,

(iii) the critical depth occurs on the subdam.

According to the assumption (i), the following equation is obtained;

$$
\frac{h_{2}}{h_{1}}=\frac{1}{2}\left(\sqrt{1+8 F^{2}}-1\right)
$$

From the assumption (ii) and the application of the Bernoulli's theorem to the flow between sections II and III, the following relation is derived:

: Present address: Laboratory of Land-Improvement, Faculty of Agriculture, Saga University, Saga 840 


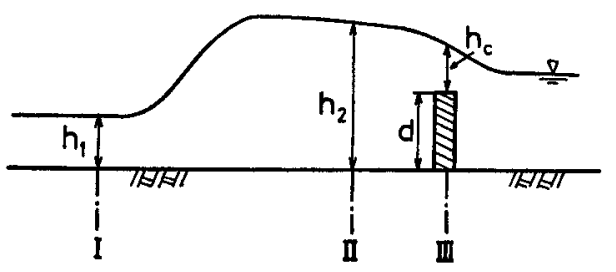

Fig. 1. Definition sketch.

$$
\frac{v_{2}^{2}}{2 g}+h_{2}=\frac{v_{3}^{2}}{2 g}+\left(h_{c}+d\right)
$$

where $v_{2}$ and $v_{3}$ are the mean velocity at sections II and III, respectively, $h_{2}$ is the water depth at section II and $h_{c}\left(=h_{3}\right)$ is the critical water depth at section III. From Eqs. (2) and (3), Eq. (1) is obtained.

According to assumption that energy losses between sections II and III would be the function of overflow-coefficient of the weir, Forster and Skrinde (1950) suggested the following equation;

$$
\begin{aligned}
& N^{2}+N=0.664(N-r)^{3}\left[0.770+0.847\left(\frac{N-r}{N}\right)^{2}+0.234\left(\frac{N-r}{N}\right)^{4}+0.225\left(\frac{r}{N-r}\right)\right. \\
& +0.248 \frac{r}{N}\left(\frac{N-r}{N}\right)+0.068\left(\frac{N-r}{N}\right)^{3} \times \frac{r}{N}+0.016\left(\frac{r}{N-r}\right)^{2}+0.018\left(\frac{r}{N}\right)^{2} \\
& \left.\quad+0.005\left(\frac{N-r}{N}\right)^{2} \times\left(\frac{r}{N}\right)^{2}\right]
\end{aligned}
$$

where $N=h_{2} / h_{1}=\frac{1}{2}\left(\sqrt{1+8 F^{2}}-1\right)$ and $r=d / h_{1}$. By applying the law of momentum conservation to the flow between sections II and III, the following equation is obtained :

$$
\frac{d}{h_{1}}=\frac{1}{2}\left(\sqrt{1+8 F^{2}}-1\right)-\left(\frac{1}{2}\left(1+4 F^{2}-\sqrt{1+8 F^{2}}\right)+3 F^{\frac{4}{3}}-2 F^{2}-1\right)^{\frac{1}{2}}
$$

Figure 2 shows the comparison of Eqs. (1), (4) and (5).

Considering the external forces that act on the water by subdam in a jump, the following equation is obtained (see Fig. 3) ;

$$
\frac{q}{g}\left(v_{1}-v_{2}\right)=\frac{1}{2}\left(h_{2}^{2}-h_{1}^{2}\right)+\frac{P_{x}}{w}
$$

where $q$ is the discharge per unit width of the channel, $v_{1}$ and $v_{2}$ are the mean velocity at sections I and II, respectively, $h_{1}$ is the depth of the beginning point of a jump, $h_{2}$ is the downstream depth of subdam, $w$ is the specific weight of water and $P_{x}$ is the external forces that act on the water in a jump. Substituti ng $C_{D}=h_{2} / h_{1}, \lambda=F^{2}=q^{2} / g h_{1}^{3}$ and $R_{x}=P_{x} / \frac{w h_{1}^{2}}{2}$ to $E q$. (6),

$$
C_{p}-\left(2 \lambda+1-R_{x}\right) C_{p}+2 \lambda=0
$$




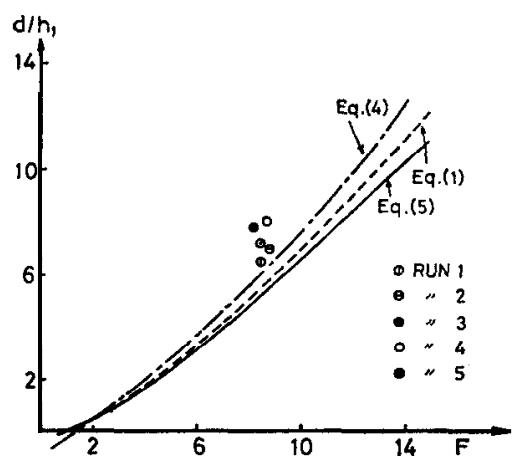

Fig. 2. Variation of relative height of subdam with $F$.

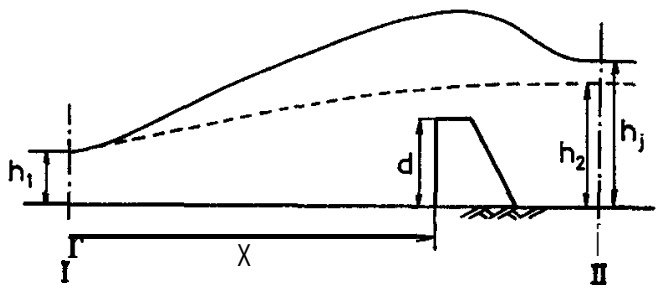

Fig. 3. Definition sketch.

When $\mathrm{X}$ is assumed as the distance from the beginning point of a jump, the depth (h) at the front of subdam will be given by the following equation;

$$
h=\left\{1+\left(\frac{X}{L}\right)(N-1)\right\} h_{1}
$$

where $N=h_{j} / h_{1}=\frac{1}{2}\left(\sqrt{1+8 F^{2}}-1\right), h$, is the conjugate depth to $h$, and $L$ is the length of the roller. The depth (h) does not, however, change linearly in practice, so that $\boldsymbol{E q}$. (8) should be corrected as follows:

$$
\begin{gathered}
h=k h_{1}=C_{H}\left\{1+\left(\frac{X}{L}\right)(N-1)\right\} h_{1} \\
k=C_{H}\left\{1+\left(\frac{X}{L}\right)(\mathrm{N}-1)\right)
\end{gathered}
$$

where $C_{H}$ is the correction-coefficient. From $\boldsymbol{E q}$. (9), the mean velocity (v) at the section $\mathrm{X}$ is

$$
v=v_{1} / k
$$

As the total dynamic water pressure acting on the front of subdam is generally given by the expression;

$$
C_{D} \rho v^{2} d / 2
$$

$\left(C_{D}\right.$ : coefficient of drag), the following equation is obtained by using $\boldsymbol{E q} .(11)$; 


$$
C_{D} w \lambda h_{1} d / 2 k^{2}
$$

The hydrostatic pressures acting on the front and the back of subdam are

$$
w d\left(k h_{1}-d / 2\right)
$$

and

$$
-w d\left(k^{\prime} h,-d / 2\right)
$$

respectively, where $k^{\prime}$ is the ratio of a real depth to a theoretical conjugate depth $\left(h_{i}\right)$ to $h$. From Eqs.(12), (13) and (14),

$$
\begin{aligned}
R_{x} & =P_{x} / \frac{w h_{1}^{2}}{2}=\left[C_{D} w \lambda h_{1} d / 2 k^{2}+w d\left(k h_{1}-d / 2\right)-w d\left(k^{\prime} h_{j}-d / 2\right)\right] / \frac{w h_{1}^{2}}{2} \\
& =m^{\prime}\left(C_{D} \lambda / k^{2}+2 k-2 k^{\prime} N\right)
\end{aligned}
$$

where $\boldsymbol{m}^{\prime}=d^{\prime} / h_{1}$ and $N=h_{j} / h_{1}$. Substituting Eq. (15) to Eq. (7),

$$
C_{P}^{3}-\left[2 \lambda+1-m^{\prime}\left(C_{D} \lambda / k^{2}+2 k-2 k^{\prime} N\right)\right] C_{i^{\prime}}+2 \lambda=0
$$

According to Eq. (16), the depth $\left(h_{1}\right)$ is deduced from the experimental values of $C_{D}, k$ and $k$ '.

\section{Method for determining the setting place of the subdam}

The results of Ralph's experiments (1950) have shown that the forces acting on the subdam in a jump decrease rapidly to a minimum as the downstream end of the jump is moved upstream a position approximately over the subdam (see Fig. 4). Then the force increases slowly to a constant value as the jump is moved farther the upstream. From the facts described above, it could be estimated that the distance between the beginning point of a jump and the subdam should be approximately equal to the length of the jump. But the length of a jump is not predicted. Therefore, the following experimental

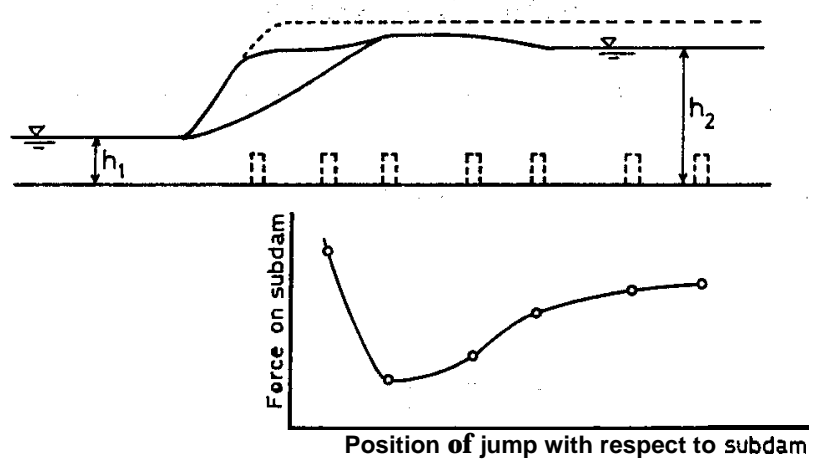

Fig. 4. Force on the subdam at various positions of the subdam (by Ralph, 1950).

expression by Bakhmeteff and Matzke (1938) must be relied on to have a usef ul design ;

$$
\mathrm{X}=(4.5-5) h \text {, }
$$

where $\mathrm{X}$ is the distance between the beginning point of a jump and the subdam, 
and $h$, is the conjugate depth to the beginning depth of a jump.

\section{Jump in sloping channels}

Common forms of the hydraulic jump in sloping channels have been classified into four general cases as shown in Fig. 5 (Kindsvater, 1944).

Case 1, with the entire on the horizontal floor, is the jump in horizontal channel. Case 2 is the jump with the toe of the roller on the slope and the end of the roller on the horizontal floor. Case 3 is the jump with the toe of the roller on the slope and the end at the junction of the sloping and horizontal floor. Case 4 is the jump with the entire roller on the slope.

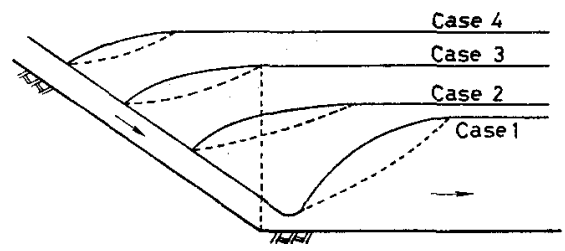

Fig. 5. Basic cases of the hydraulic jump in sloping channels.

In case $1, \boldsymbol{E} \boldsymbol{q}$. (1) is applicable. Case 2 is intermediate between cases 1 and 3 , but either the theory of case 1 or that of case 3 is not applicable to this case. It is proved from the experimental results that case 3 can be dealt with the same pattern as case 4 . Case 3 is analyzed theoretically as follows.

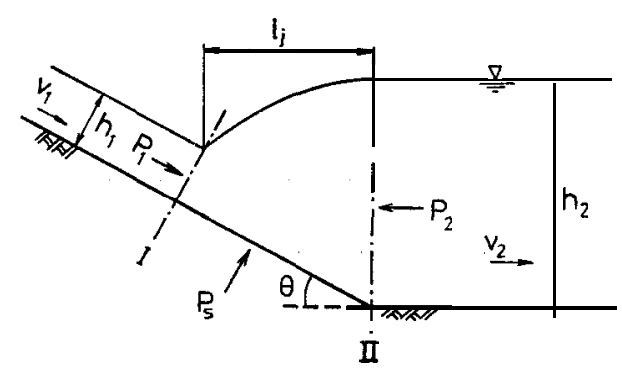

Fig. 6. Elements of a hydraulic jump.

Figure 6 shows case 3 with slope angle 8 . In Fig. $6, v_{1} \cos \theta$ is the horizontal component of the average velocity in section I at the toe of the jump, and $v_{1}$ is the average velocity in section II at the end of the jump. By applying the law of momentum conservation between sections I and II, the following equations are given for the horizontal direction,

$$
\frac{w}{g} q\left(v_{2}-v_{1} \cos \theta\right)=P_{1} \cos \theta-P_{2}+P_{5} \sin \theta
$$

and for the vertical direction,

$$
\frac{w}{g} q v_{1} \sin \theta=P_{S} \cos \mathrm{e}-\mathrm{p}, \sin \mathrm{e}
$$


where $P_{1}$ and $P_{2}$ are the static pressure in section $\mathrm{I}\left(=w / 2 \cdot h_{1}^{2} \cos \theta\right)$ and in section II $\left(=\mathrm{w} / 2 \cdot h_{2}^{2}\right)$, respectively. $\quad P_{s}$ is the static pressure acting on the slope between sections I and II given as follows:

$$
P_{S}=\frac{w}{2}\left\{h_{1}^{2} \tan \theta+l_{j}\left(\frac{h_{1}}{\cos \theta}+h_{2}\right)\right\}
$$

From Eqs. (18), (19), the continuity equation $: h_{1} v_{1}=h_{2} v_{2}$ and $F=v_{1} / \sqrt{g} h_{1}$,

$$
h_{2}^{3}-\left(h_{1}^{2}+2 \sec \theta F^{2} h_{1}^{2}\right) h_{2}+2 F^{2} h_{1}^{3}=0
$$

Letting $\mathrm{N}$ be $N=h_{2} / h_{1}, E q$. (20) becomes

$$
N^{3}-\left(1+2 \sec \theta F^{2}\right) N+2 F^{2}=0
$$

In the case of $\theta=0, E q$. (21) reduces to

$$
N^{3}-\left(1+2 F^{2}\right) N+2 F^{2}=0
$$

A root of this equation is $\mathrm{N}=\frac{1}{2}\left(\sqrt{1+8 F^{2}}-1\right)$, which is identical with $E q$. (2). Figure 7 which shows the relations between $\mathrm{N}$ and $F$ is respected by $E q$. (21) using $\theta$ parameter.

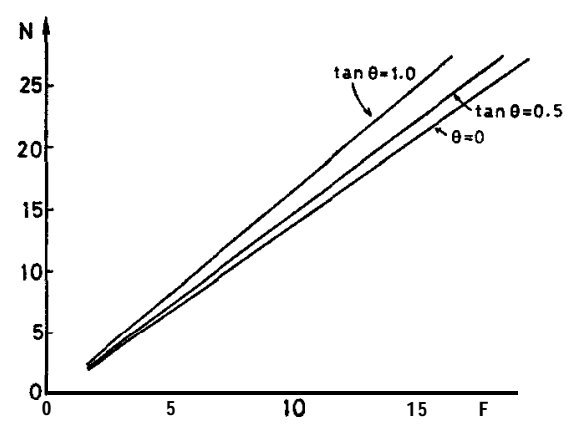

Fig. 7. Relation between $\mathrm{N}$ and $F(E q .21)$.

\section{Energy losses in hydraulic jump}

By applying Bernoulli's theorem to the flow between sections I and II (see Fig. 6), the following relation is given;

$$
l_{,} \tan \theta+h_{1} \cos \theta+\frac{v_{1}^{2}}{2 g}=h_{2}+\frac{v_{2}^{2}}{2 g}+I_{g}
$$

where $I_{k}$ is the specific energy loss.

From the continuity equation $v_{1} h_{1}=v_{2} h_{2}, E q$. (22) becomes

$$
I_{g}=\frac{h_{1}}{2} F^{2}\left(1-\frac{1}{N^{2}}\right)+h_{1}(\cos \theta-N)+l_{,} \tan \theta
$$

where $\mathrm{N}=h_{2} / h_{1}$. From Eq. (21) and $i_{z}=I_{g} / h_{1}, E q$. (23) becomes

$$
t_{g}=\frac{\left(N^{2}-1\right)^{2}}{4 N(N \sec \theta-1)}+\cos \theta-N+\frac{l_{j}}{h_{11}} \tan 0
$$


For $\theta=0$, Eq. (24) reduces to

$$
\iota_{g 0}=\frac{(N-1)^{3}}{4 \mathrm{~N}}
$$

A better expression of energy loss in the jump is obtained by expressing it as percentage of the initial energy. From Fig. 6,

$$
\% \text { loss }=E=\frac{100 I_{g}}{l_{j} \tan \theta+h_{1} \cos \theta+\frac{v_{1}^{2}}{2 g}}
$$

Using Eqs. (23) and (21),

$$
E=\frac{4\left(l_{j} / h_{1} \cdot \tan \theta+\cos \theta-N\right) N(N \sec \theta-1)+\left(N^{2}-1\right)^{2}}{4\left(l_{i} / h_{1} \cdot \tan \theta+\cos \theta\right) N(N \sec \theta-1)+N^{2}\left(N^{2}-1\right)} \times 100
$$

For $\theta=0$, Eq. (27) reduces to

$$
E_{0}=\frac{(N-1)^{3}}{N\left(N^{2}+N+4\right)} \times 100
$$

\section{EXPERIMENTAL ARRANGEMENT}

Experimental equipment was the model (reduced to a scale of 1/50) of the spillway attached to Gōsho-dam (in Ukiha-Machi, Fukuoka Pref.). The equipment is shown in Figs. 8-10. The inlet was fan-shaped. Chute was a rectangular flume $54.2 \mathrm{~cm}$ wide $(27.1 \mathrm{~m}$ in prototype. From now on, the values in parentheses mean the dimension of the prototype). Slope of chute was 1 on 2 . A height between the inlet floor and the stilling basin floor was $114.8 \mathrm{~cm}(57.4$ $\mathrm{m})$. The design floor discharge of this spill-way was $Q=49.8 \mathrm{l} / \mathrm{sec}\left(880 \mathrm{~m}^{3} / \mathrm{sec}\right)$. For this discharge $(\mathrm{Q})$, the depth at the beginning of a jump was $h_{1}=1.9 \mathrm{~cm}$ $(0.942 \mathrm{~m})$. By applying Iwasaki formula (Eq. 1), the height of subdam was given with $d=15.6 \mathrm{~cm}(7.8 \mathrm{~m})$, and then from Eq. (17) the length of stilling basin was obtained with $\mathrm{X}=144 \mathrm{~cm}(72 \mathrm{~m})$. Referring to these values, experi-

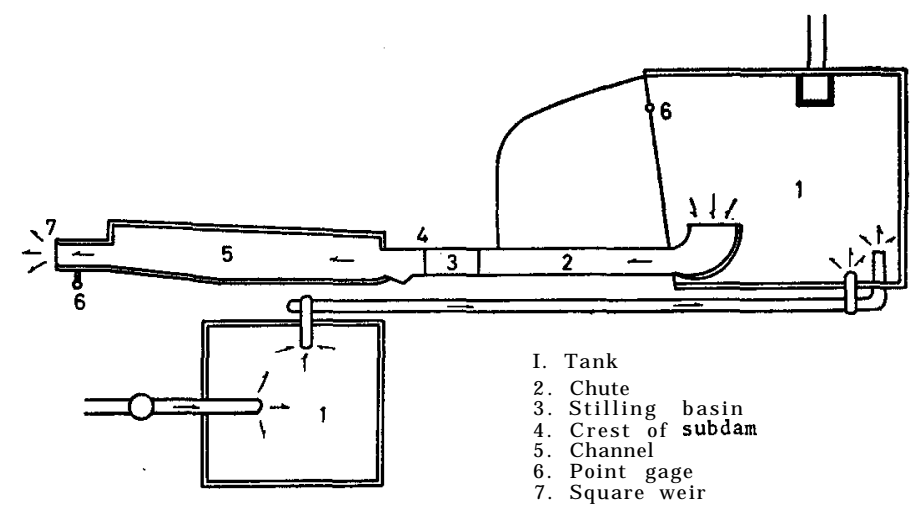

Fig. 8. Arrangement of experimental apparatus. 


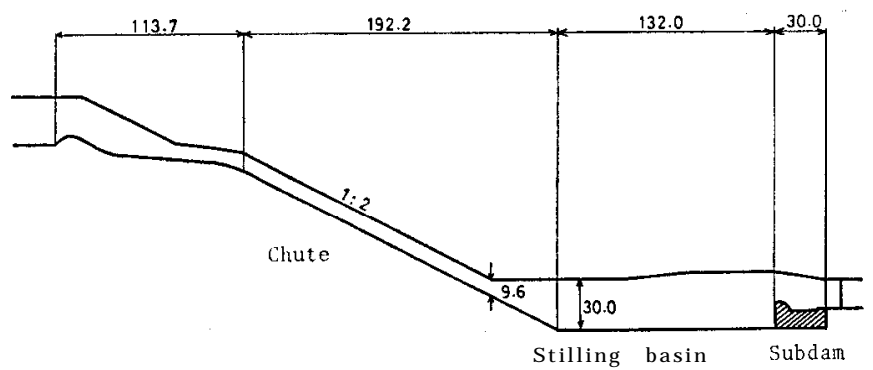

Fig. 9. Experimental apparatus (cm).

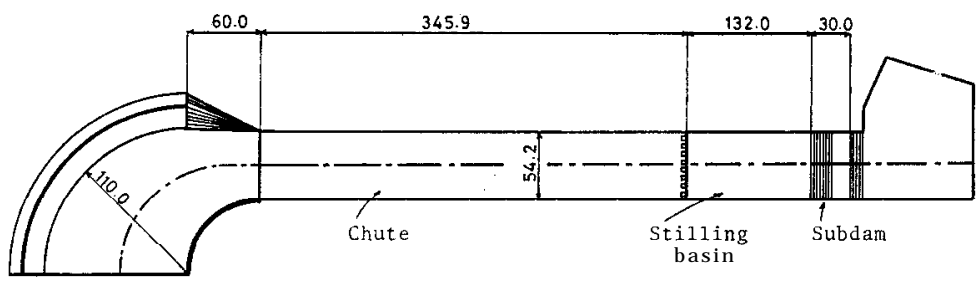

Fig. 10. Experimental apparatus (cm).

Table 1. Experimental details.

\begin{tabular}{|c|c|c|c|c|c|}
\hline $\mathrm{X} \mathrm{cm}$ & $d \mathrm{~cm}$ & $v_{1} \mathrm{~cm} / \mathrm{s}$ & $h_{1} \mathrm{~cm}$ & $F$ & Run \\
\hline 144 & 15.6 & $\begin{array}{l}385 \\
400 \\
409 \\
421\end{array}$ & $\begin{array}{l}1.01 \\
1.5 \% \\
1.82 \\
2.23 \\
2.39\end{array}$ & $\begin{array}{r}11.12 \\
9.78 \\
9: 47 \\
8.75 \\
8.70\end{array}$ & 1 \\
\hline 144 & 17. 2 & $\begin{array}{l}329 \\
37 \% \\
404 \\
410 \\
421\end{array}$ & $\begin{array}{l}0.75 \\
1.59 \\
1.99 \\
2.40 \\
2.70\end{array}$ & $\begin{array}{r}12.14 \\
9.60 \\
9.15 \\
8.45 \\
8.1 \%\end{array}$ & 2 \\
\hline 144 & $1 \% .9$ & $\begin{array}{l}336 \\
381 \\
390 \\
401 \\
415\end{array}$ & $\begin{array}{l}0.84 \\
1.39 \\
1.81 \\
2.41 \\
2.5 \%\end{array}$ & $\begin{array}{r}11.71 \\
10.32 \\
9.26 \\
8.25 \\
8.25\end{array}$ & 3 \\
\hline 134 & $1 \% .9$ & $\begin{array}{l}33 \% \\
386 \\
400 \\
411 \\
415\end{array}$ & $\begin{array}{l}0.86 \\
1.44 \\
1.74 \\
2.96 \\
2.52\end{array}$ & $\begin{array}{r}11.64 \\
10.2 \% \\
9.69 \\
8.55 \\
8.35\end{array}$ & 4 \\
\hline 124 & 15.6 & $\begin{array}{l}341 \\
395 \\
39 \% \\
409 \\
414\end{array}$ & $\begin{array}{l}0.91 \\
1.47 \\
1.94 \\
2.39 \\
2.75\end{array}$ & $\begin{array}{c}11.42 \\
10.41 \\
9.13 \\
8.45 \\
7.97\end{array}$ & 5 \\
\hline
\end{tabular}


ments were carried out under the conditions as shown in Table 1.

As the water depth was measured with manometers, the values of the observed water depth have been found higher than the measured ones because of air mixing. The velocity distributions were measured with small sized current meters and pitot tubes, and the discharge was measured with a square weir equipped at the end of the channel.

\section{EXPERIMENTAL RESULTS}

\section{Height of subdam}

Figure 2 shows that the measured relative heights $(d / h$,$) are larger than$ calculated ones by Eqs. (1), (4) and (5). This fact may be caused by the backwater due to the contraction of downstream-channel in the experiments. The selection of subdam height needs being considered the backwater into Eqs. (1), (4) and (5).

\section{Conjugate depth}

Photograph 1 shows that the jump begins in the chute, so that $\mathrm{N}$ in $E q$. (21) instead of $\mathrm{N}$ in $E q$. (9) should be used to calculate the depth $\left(h_{2}\right)$ at the downstream of the subdam from $E q$. (16). Figures 11 and 12 show $k$ in $E q$. (9) as a function of $X / l_{j}$ and $k^{\prime}$ in $E q$. (14) as a function of $X / h_{j}$ respectively. Figure 13 shows a comparison of measured and calculated values from $E q$. (16),

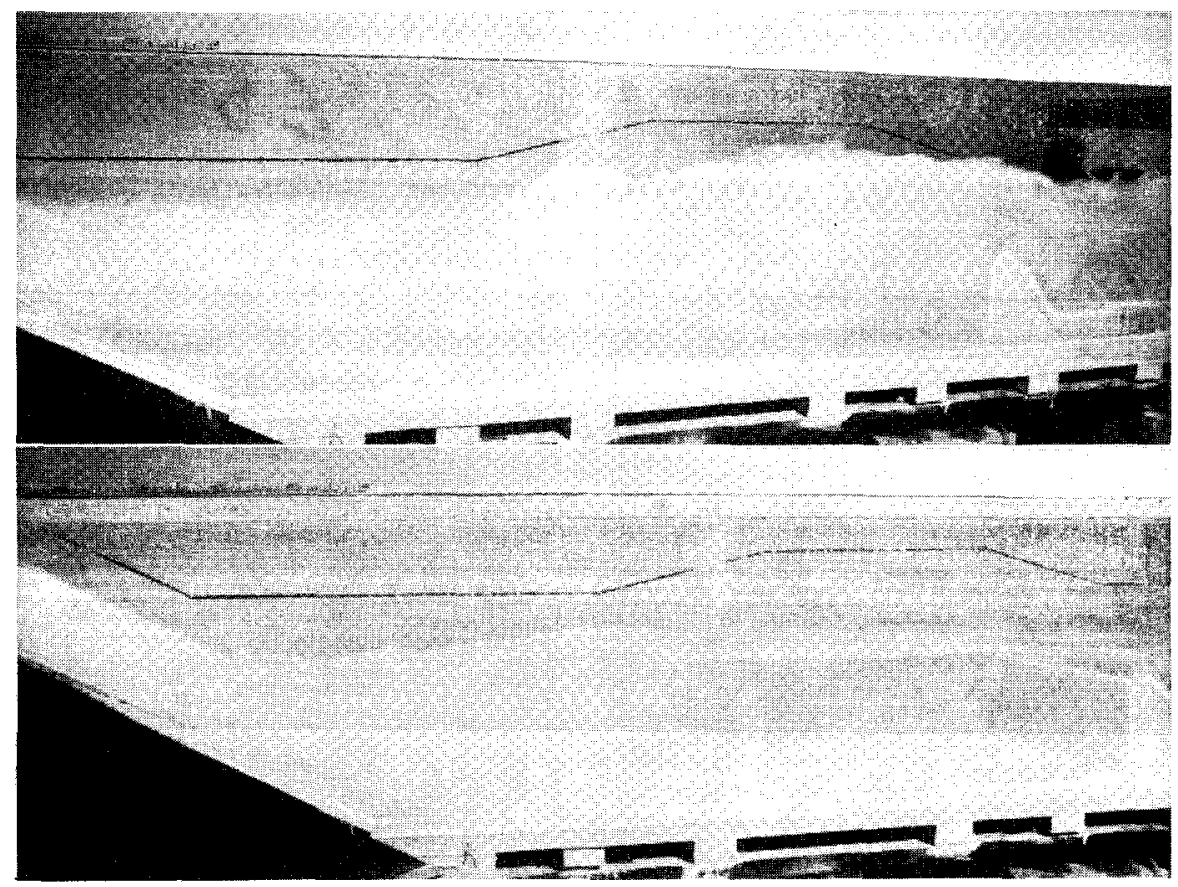

Photo. 1. Hydraulic jump in sloping channels. 


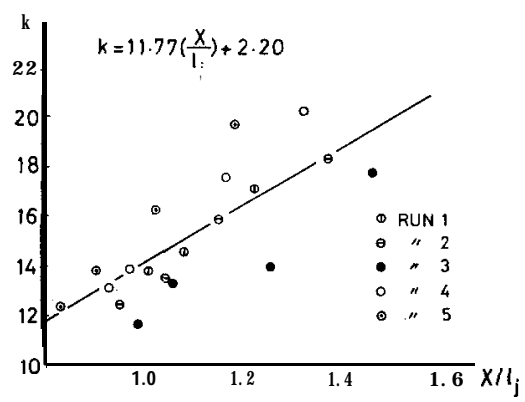

Fig. 11. Variation of $\mathbf{k}$ with $(\mathrm{X} / \mathrm{Z}$,$) .$

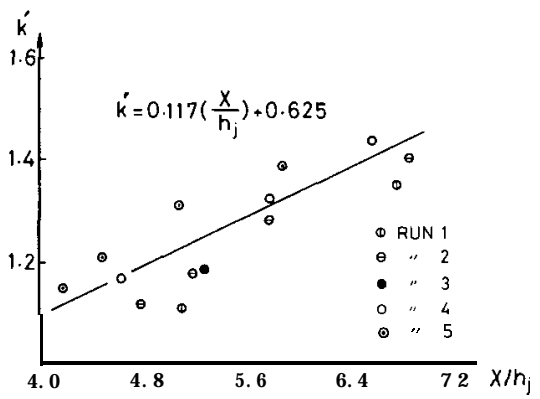

Fig. 12. Variation of $\mathbf{k}^{\prime}$ with $(\mathbf{X} / \mathbf{h}, \mathbf{)}$.

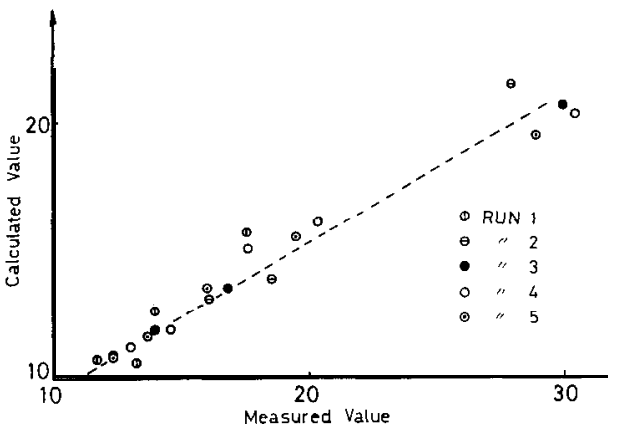

Fig. 13. Comparison of measured and calculated values.

using above results. In Fig. 13, the measured values are larger than the calculated ones. This may be attributed to the backwater due to the contraction of downstream channel.

Energy losses due to a jump in slope

When the toe of the roller is on the slope, the relation between $l_{j} / h_{1}$ and $F$ is shown in Fig. 14, that is;

$$
\frac{l_{j}}{h_{1}}=0.305 \times 10^{0.185 F}
$$


where $l_{j}$ is a horizontal distance from the toe of the jump to a junction of the sloping and horizontal floors, $h_{1}$ is a water depth at the toe of the jump, and $\boldsymbol{F}$

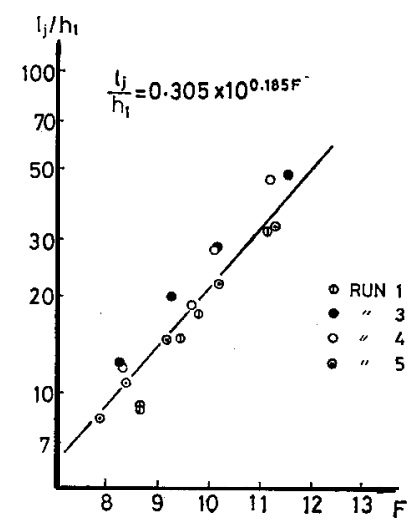

Fig. 14. Relation between $\left(l_{j} / h_{1}\right)$ and $\mathbf{F}$.

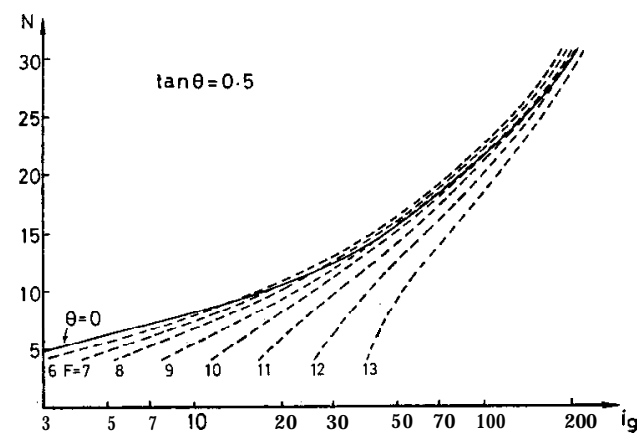

(a)

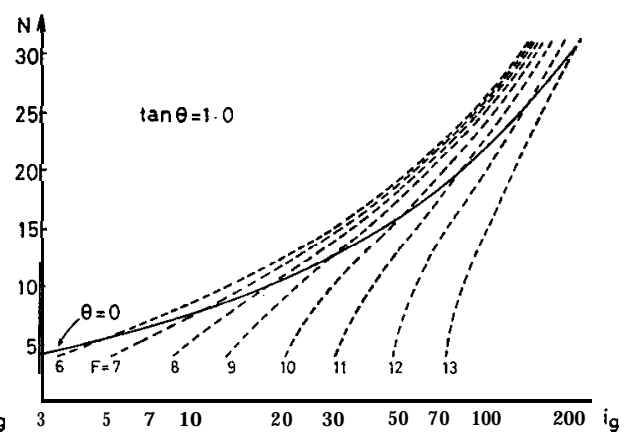

(b)

Fig. 15. Energy losses in hydraulic jump; i,.

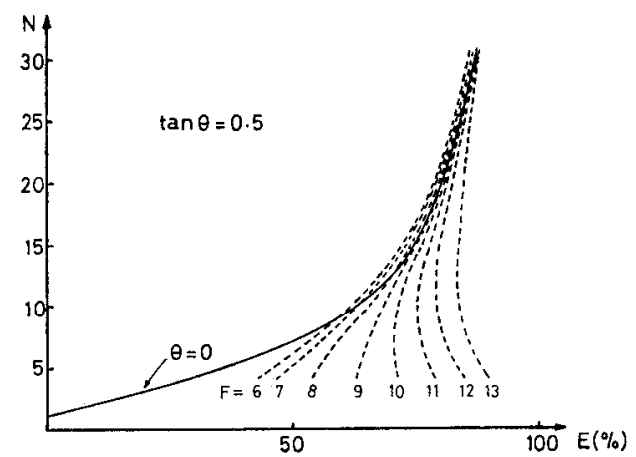

(a)

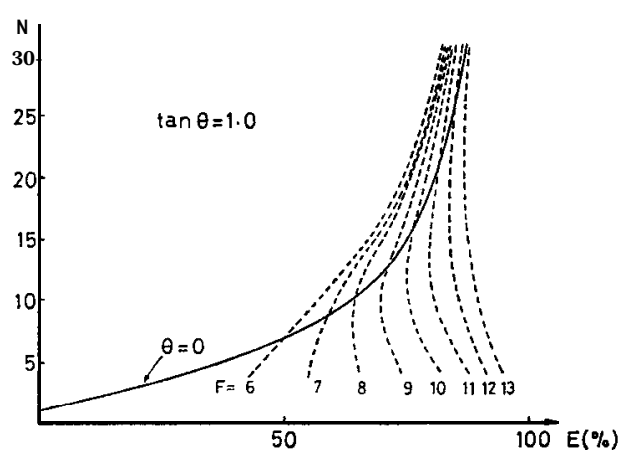

(b)

Fig. 16. Energy losses in terms of $\mathrm{N}$. 
is Froude number. Substituting Eq. (29) in Eqs. (24) and (27), values of $i_{\boldsymbol{s}}$ and $E$ are given in Figs. 15 (a), 15 (b), 16 (a) and 16 (b). In our experiments, $i_{g}=$ 25 180, $E=60 \sim 85 \%$.

\section{CONCLUSION}

1. In this paper, three methods used for determining the height of subdam were introduced, those are Iwasaki formula, Forster and Skrinde formula and a formula derived from a law of momentum conservation. But, there were no remarkable differences. Therefore, for the field planning, Iwasaki formula being relatively simple can be applied to determine the height of subdam.

2. Distance from the junction of the sloping and horizontal floors to subdam can be available about 5 times the conjugate depth (=the length of a jump).

3. The downstream depth of subdam calculated from Eq. (16), has two constant values, $k$ and $k^{\prime}$, determined by experiments. Therefore, more detailed experiments should be carried out in order to obtain values of $k$ and $k$ '.

\section{REFERENCES}

Bakhmeteff, B. A. and Matzke 1938 The hydraulic jump in terms of dynamic similarity. Trans. A.S.C.E., 101: 603-647

Forster, J. W. and R. A. Skrinde 1950 Control of the hydraulic jump by sills. Trans. A.S. C.E., 115: 973-987

Iwasaki, T. 1961 On the energy dissipator of the spillway, Proc. Tohoku-Branch, Japan. Soc. Civil Engineers, (in Japanese), p. 62

Kindsvater, C. E. 1944 The hydraulic jump in sloping channels. Trans. A.S.C.E., 109 : $1107-1154$

Ralph, M. W. 1950 Discussion on control of the hydraulic jump by sills, by J. W. Forster and R. A. Skrinde. Trans. A.S.C.E., 115: 1003-1006 